\title{
Pressure gradients in a steeppass fishway using a computational fluid dynamics model
}

\section{Authors: Kathryn Plymesser \& Joel Cahoon}

NOTICE: this is the author's version of a work that was accepted for publication in Ecological Engineering. Changes resulting from the publishing process, such as peer review, editing, corrections, structural formatting, and other quality control mechanisms may not be reflected in this document. Changes may have been made to this work since it was submitted for publication. A definitive version was subsequently published in Ecological Engineering VOL\# 108, PART A, (November 2017), DOI\# 10.1016/j.ecoleng.2017.08.035

Plymesser, Kathryn, and Joel Cahoon. "Pressure gradients in a steeppass fishway using a computational fluid dynamics model." Ecological Engineering 108, no. Part A (November 2017): 277-283. DOI: 10.1016/j.ecoleng.2017.08.035.

Made available through Montana State University's ScholarWorks scholarworks. montana.edu 


\title{
Pressure gradients in a steeppass fishway using a computational fluid dynamics model
}

\author{
Kathryn Plymesser, Joel Cahoon* \\ Civil Engineering Department, 205 Cobleigh Hall, Montana State University, Bozeman, MT 59717, United States, United States
}

\begin{abstract}
A B S T R A C T
The Alaska steeppass is a fishway used commonly in the eastern United States and in remote locations, and is an example of the many configurations of fishways, ladders, bypass channels and other structures intended to facilitate fish mobility in river systems fractured by in-stream structures. Passage success for this fishway is varied and depends on many factors including species of interest. The cause of this variation is relatively unknown and typically ascribed to "other hydraulic factors", meaning a hydraulic variable other than the mean (spatial and temporal) velocity. Attempts have been made to move from velocity-based to energy-based fish passage models to pinpoint these "other factors", however energy-based passage models rely on assumptions that may be inappropriate when applied to hydraulically complicated fishways. An assumption that has facilitated wide ranging discussions of the performance of fish ladders without the develop of very specific and detailed computational models is that pressure forces that a fish might experience can be adequately estimated using uniform flow pressure distributions. In uniform flow, the vertical pressure distribution is as if hydrostatic, and there is no pressure gradient in the horizontal plane. To test this assumption, very detailed three-dimensional hydraulics information was generated from a computational fluid dynamics (CFD) model of the steeppass to calculate the pressure. The results demonstrate the significance of considering dynamic pressure distributions when modeling the interaction between hydraulics and fish mobility.
\end{abstract}

\section{Introduction}

Engineers and ecologists work together to design fish passage structures that accommodate a desirable level of fish mobility under the constraints of the hydraulic and hydrologic setting. Designs of fish passage structures are often based on guidelines developed from observation. As fishways are expected to pass a wider range of target species at higher rates these guidelines can be insufficient. A mechanistic approach was introduced by Behlke $(1987,1991)$, Behlke et al. (1993) to use the concepts of fish power and energy expenditure to evaluate fish negotiating passage structures. This method proposes that by summing the hydraulic forces acting on a swimming fish the propulsive force can be estimated and by extension to a particular hydraulic challenge the energy and power requirements can be calculated. Estimates of energy required to pass a particular hydraulic challenge could be compared to observed power capabilities and energetic data for fish that have successfully passed structures to determine if the challenge is reasonable for a particular species. This method has gained very little traction in fish passage design but could be used to compare the energy required for fish to pass different structures or negotiate different swim pathways in a single structure. Behlke acknowledged that one-dimensional and steady analyses formed the framework for his approach which was specific to culverts. Fish passage researchers have applied Behlke's ideas to include other structures and the influence of three-dimensional flow using numerical models. Access to CFD model predictions of fishway hydrodynamics opens the door to making more comprehensive energy estimates as shown by Khan (2006), Blank (2008) and Plymesser (2014). These three studies relied heavily on uniform flow pressure distributions to estimate the forces that influence energetic expenditure. The objective of this study is to investigate the magnitude and patterns of the pressure gradients that may be expected in a steeppass fishway.

\section{The steeppass fishway}

Fishways are structural amendments that ameliorate problems presented by in-stream barriers that reduce fish mobility. The Alaska steeppass fishway is used extensively on coastal streams, originally developed by Ziemer (1962) for use at sites that were difficult to access with construction equipment and materials. The Alaska steeppass uses a 
series of symmetric, closely spaced baffles to dissipate energy and reduce water velocities in the chute. The steeppass was originally designed to provide upstream passage for salmon in Alaska; however it has also been used to pass non-salmonid species in locations outside Alaska (Haro et al., 1999).

The Steeppass fishway was studied by Ziemer (1962), Rajaratnam and Katopodis (1991), and Odeh (1993) using full-scale physical models to explore one-dimensional water velocities, flow rates and water surface profiles. Results of all three of these one-dimensional physical studies are comparable and indicated that the Steeppass fishway is an efficient energy dissipater, particularly so at steep slopes, as evidenced by the water velocities measured in the fishway. The bulk water velocity ranges from 0.46 to $1.07 \mathrm{~m} / \mathrm{s}$ over the typical operating range of inlet heads (Ziemer, 1962; Odeh, 1993). Another approach to the study of steeppass hydraulics was to measure velocities on a closely spaced three-dimensional grid throughout the structure to characterize flow patterns (Wada et al., 2000).

\section{The computational fluid dynamics (CFD) model}

The authors used commercial software to develop a computational model of a deepened A40 steeppass ("A" or "C" specifies nuances of the fishway geometry, " 40 " specifies that the fishway wall height is 40 inches, rather than the 27 inch standard "A"). Flow 3D software (Flow Science, 2012) uses a finite-volume, transient solution to the Reynoldsaveraged Navier-Stokes equations. The general CFD process and implementations specific to modeling the Model A40 steeppass are detailed in Plymesser (2014). The simulated steeppass fishway had an upstream inlet depth of $91.4 \mathrm{~cm}$ and a nominal downstream slope of 1:8 (vertical to horizontal) and the baffles are spaced $25.4 \mathrm{~cm}$. In summary:

- a volume-of-fluid method was used to define the fluid surface (Hirt and Nichols, 1981) and the fluid surface was located a sufficient distance beneath the upper boundary to the domain that it did not interact with the boundary,

- a two-equation turbulence model was selected to adequately describe the turbulent length and time scales, with renormalizationgroup methods (Yakhot and Smith, 1992) and transport equations similar to the standard k- $\varepsilon$ model (the RNG model generally has wider applicability than the $\mathrm{k}-\varepsilon$ model as the constants that are found empirically for the k- $\varepsilon$ model are derived explicitly in the RNG model),

- the computational domain was divided into a $7.62 \mathrm{~mm}$ mesh of fixed hexahedral cells with solutions progressing in space and time and with the solid model of the fishway located within the computational domain,

- the size of the cells required was small to resolve the flow field near the ends of the thin baffles,

- the air entrainment routine in Flow3D was not implemented, the required calibration information for the specific model was not available,

- the boundary conditions on the inlet and outlet to the domain were pressure boundaries with prescribed water surface elevations,

- the bottom and sides of the domain were defined as no-slip wall boundaries and the upper surface of the computational domain was a symmetry boundary,

- the model was initiated with static water filling the interior of the model that was not occupied by the solid fishway, with a water surface connecting the prescribed inlet and outlet water levels,

- the solid components of the steeppass were assigned a roughness height of zero, appropriate because the form roughness of the baffles dominates and the influence of the roughness height of the aluminum plate is minimal in comparison.

The CFD model output was compared to measurements from the full-scale physical model at the S.O. Conte Anadromous Fish Branch
(Plymesser, 2014). The water surface profile is a CFD model-generated outcome and was compared to observed values. The RMSD between the observed and predicted water surfaces was $37 \mathrm{~mm}(-3.3 \%$ percent error) for the simulation discussed herein. In three other configurations of fishway slope and inlet head level not detailed herein, the CFD model predicted the observed water surface profile with between $-0.6 \%$ and $-5.9 \%$ error. Over all four comparisons, the model consistently predicted the observed water surface elevation including the steady undulations and shape of the profile. The average error between modeled and observed water surface elevations was on the order of the height of the dynamic waves observed on the water surface. The CFD model output was also compared to standard rating curves for the steeppass fishway (Odeh, 1993). The volumetric flow rate is a CFD model generated output in the framework of the boundary conditions used. For the simulation discussed herein, the CFD generated flowrate differed from the rating curve flow rate by $7.2 \%$. Over all four hydraulic combinations, the difference was $7 \%$. Two three-dimensional mesh size simulations were performed on the hydraulic combination having low inlet head and shallow slope to ascertain the adequacy of the spatial resolution. The coarse mesh had $9.14 \mathrm{~mm}$ cells and a slightly thicker baffle thickness (reducing the need for clarity at the sharp edges of the baffle) and the fine grid had $7.62 \mathrm{~mm}$ cells and a thinner baffle thickness. The structured mesh model that was used required a fine mesh size to accommodate thin, angle baffles in the steeppass fishway. Any cell size less than $7.62 \mathrm{~mm}$ resulted in a model that exceeded the computational facilities available at the time. The two approaches resulted in water surface profiles within $0.4 \%$ of each other. Because the coarse and fine meshes predicted similar water surface profiles for this hydraulic configuration, no further refinements were made and the coarse mesh was used for all simulations. All simulations were carried out until the final $10 \mathrm{~s}$ of model time had less than $0.1 \%$ variation in volume of fluid. All simulations required $20-30 \mathrm{~s}$ of model time to achieve stationarity.

\section{Theory and computations}

The two-dimensional vector representation of Fig. 1 shows the force balance on a particle (or a relatively small volume such as a differential element) as it passes through a moving flow field. Forces identified on the differential scale can be integrated over the body or surface of the fish to arrive at the magnitude and direction of the forces that impact energetics. The nature of CFD output, closely spaced results on a threedimensional grid, provides an effective framework for studying the force balance. This process is confounded by the presence of the swimming fish which impacts the flow field. Recent advances in CFD modeling have included numerical studies of the interaction between fluid flow and fish locomotion (Ren et al., 2016). In the current project, the CFD model was of the flow field in the fishway and did not include a model of the fish.

The steeppass geometry generates a complex flow field (e.g. velocities, pressures, forces) that appears statistically steady but is actually very diverse in space, and at any point in space is unsteady in time. The contributions to the force balance on the small volume shown in Fig. 1 are the weight $(\mathbf{W})$, the net pressure force $\left(\mathbf{F}_{\mathrm{P}}\right)$, the net viscous or shear force $\left(\mathbf{F}_{S}\right)$, and the mass force $\left(\mathbf{F}_{\mathrm{M}}\right)$. All these forces may have components in each of the three cardinal directions (the components in the ydirection are not shown).

The resultant viscous or shear force, $\mathbf{F}_{\mathrm{S}}$, can be calculated by integrating the shear stress over the area of the object. The mass force, $\mathbf{F}_{\mathrm{M}}$, is the result of the object accelerating (or decelerating) according to Newton's second law and can include the fluid near the object (Webb, 1975) due to the no-slip condition between the object and the fluid (virtual mass). In some settings, the Basset-Boussinesq force that describes the effect of the temporal delay in the development of the boundary layer of an accelerating object is added to the mass force.

The net vertical pressure force $\left(\mathbf{F}_{\mathrm{Pz}}\right)$ is often referred to as the 


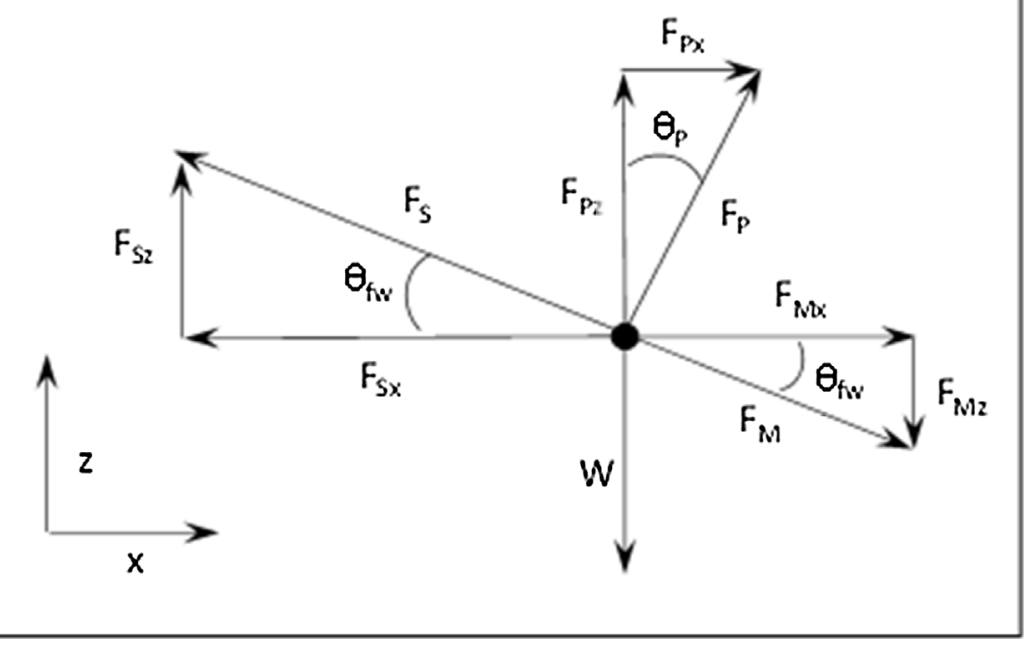

Fig. 1. A two-dimensional representation of the force balance on a small volume in a moving flow field.

buoyant force. In static water Archimedes' principle applies and the buoyant force is coincident with the gravitational vector and equal to the volume of the fluid displaced by the object multiplied by the specific weight of the fluid. More generally the resultant pressure force is the negative of the del operator applied to the pressure field, multiplied by the volume of the object in question

$\mathbf{F}_{\mathbf{P}}=(-\nabla \mathbf{P})$

Eq. (1) is applicable to a particle or differential element with pressure gradients in any direction. Eq. (1) would fall short in cases where the pressure gradients vary spatially over the surface of the object due to hydrodynamic phenomena associated with either a complex flow field or movement of a non-rigid body. In that case the resultant pressure force acting on a body at any moment in time could be calculated as the integral of pressure over the surface area of the object.

Because the focus of this paper is the role and complexities of the pressure forces on fish energetics, it is relevant to mention some of the simplifications to Fig. 1 that have been applied in previous work. In the approach where the force balance is approximated by uniform and steady conditions:

- the mass force $\left(\mathbf{F}_{\mathrm{M}}\right)$ of the fish and nearby fluid and the BassetBoussinesq force are zero due to steady conditions (the fish is not accelerating and the fluid velocity field is steady),

- the vertical component of the shear stress or viscous force $\left(\mathbf{F}_{\mathrm{Sz}}\right)$ force is negligible,

- the vertical component of the pressure force resultant is calculated as the buoyancy force using Archimedes law, but with constant vertical pressure gradient, and

- the horizontal components of both the pressure and shear stress resultants are combined into a single vector representing the overall "drag" force, $\mathbf{F}_{\mathrm{D}}$.

The drag force is difficult to determine experimentally for a fish because of the undulating body motions of live fish during propulsion. Estimates have been proposed based on prismatic bodies immersed in a moving fluid. For example, the traditional formula for the coefficient of drag on a flat plate with a turbulent boundary layer has been adjusted using a dynamic shape coefficient (Webb, 1975).

To calculate the pressure gradient in Eq. (1) from the CFD model output:

$\nabla \mathrm{P}=\partial \mathrm{P} / \partial \mathrm{x}+\partial \mathrm{P} / \partial \mathrm{y}+\partial \mathrm{P} / \partial \mathrm{z}$

In Eq. (2), each partial derivative at point $\mathrm{i}$ in the computational grid was estimated as a second-order central finite difference:

$(\partial \mathrm{P} / \partial \mathrm{x})_{\mathrm{i}} \approx\left(\mathrm{P}_{(\mathrm{i}+1)}-\mathrm{P}_{(\mathrm{i}-1)}\right) /\left(\mathrm{x}_{(\mathrm{i}+1)}-\mathrm{x}_{(\mathrm{i}-1)}\right)$

Similar finite difference approximations were used in the $y$ and $z$ directions. The pressure gradients were examined on a square spatial grid with $\Delta \mathrm{x}=\Delta \mathrm{y}=\Delta \mathrm{z}=8.1 \mathrm{~mm}$. Pressure gradients are presented in the coordinate system coincident with the floor of the fishway, transforming the $\mathrm{x}$ (horizontal) and $\mathrm{z}$ (coincident with gravity) coordinates. This transformation allows examination of the results relative to the sloping fishway (nominally $1 \mathrm{~V}: 8 \mathrm{H}$ in this case). The y components are identical in either framework and do not require transformation.

\section{Results and discussion}

The pressure gradients predicted by the CFD model are at an instant in time after the model had reached stationarity (i.e., not time-averaged) and are presented at the locations indicated in Fig. 2. The water surface shown in Fig. 2 is not to scale. The water surface was $91 \mathrm{~cm}$ above the invert at the inlet and for this trial remained in that range throughout the fishway length, showing neither drawdown or backwater characteristics. The pressure gradients are presented along two longitudinal pathways, chords 1 and 2, and at a portion of a vertical cross where the flow is not obstructed by the baffles (the unshaded area central to the fishway cross section in Fig. 2).

Fig. 3 shows the pressure gradients along chord 1 that is parallel to the fishway floor and walls and coincident with the direction of the predominant water velocity, at the position in the cross section noted in Fig. 2. Chord 1 is at a location that is heavily influenced by the baffles but far enough away that a fish could occupy the space. Fig. 3 also indicates the constant hydrostatic pressure gradients in the $x^{\prime}(0 \mathrm{kPa}$ / $\mathrm{m}), \mathrm{y}(0 \mathrm{kPa} / \mathrm{m})$ and $\mathrm{z}^{\prime}(-9.71 \mathrm{kPa} / \mathrm{m})$ directions for comparison.

The force that results from the pressure gradient in the $\mathrm{x}^{\prime}$ direction has the effect of propelling or retarding the fish along chord 1 with a positive gradient resulting in a propelling force and a negative gradient resulting in a retarding force. The $\mathrm{x}^{\prime}$-direction pressure gradient (dP/ $\mathrm{dx}$ ') along this chord 1 varies from $-9.43 \mathrm{kPa} / \mathrm{m}$ to $+1.57 \mathrm{kPa} / \mathrm{m}$. The $\mathrm{y}$ and ' $\mathrm{z}$ direction gradients result in forces that act to move a fish either side to side (y-direction) or towards or away from the floor (z'-direction). The magnitudes of the gradients in the $y$-direction range from $-3.14 \mathrm{kPa} / \mathrm{m}$ to $11.00 \mathrm{kPa} / \mathrm{m}$. The magnitudes of the gradient in the $\mathrm{z}-$ direction range from $-12.57 \mathrm{kPa} / \mathrm{m}$ to $-7.06 \mathrm{kPa} / \mathrm{m}$. The magnitudes of these pressure gradients are substantial when contrasted against the steady and uniform gradients. Forces resulting from pressure gradients of these magnitudes oscillating along a fish swim path would cause 

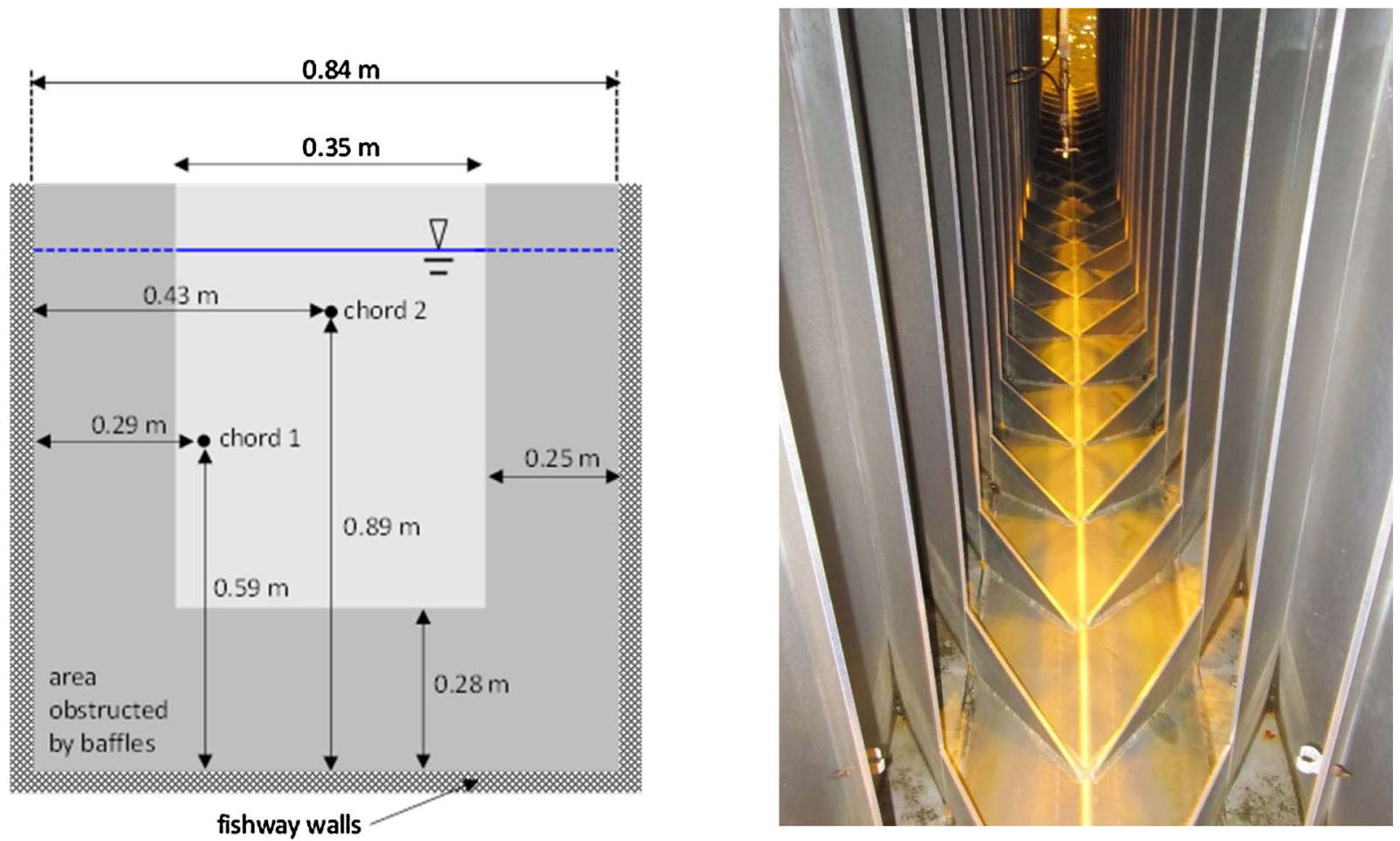

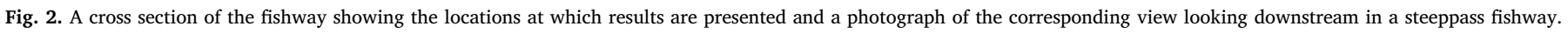

remarkable "pushing and pulling" on the fish in all three dimensions. Not only are the magnitudes of these pressure differentials high, but they change quickly over a span of $0.25 \mathrm{~m}$ (the downstream distance between baffles). This results in dynamic changes in the pushing, pulling, lifting, and tilt that a fish experiences in this fishway when swimming along this chord.

The pressure gradients along chord 2 are shown in Fig. 4. Chord 2 is located further from the baffles at a location higher in the water column than chord 1 as noted in Fig. 2. The pressure gradients along chord 2 exhibit less dramatic variation as they are under reduced influence from the baffles. Gradients along this baffle range from $-10.1 \mathrm{kPa} / \mathrm{m}$ to $0.85 \mathrm{kPa} / \mathrm{m}$. These are skewed to the negative because this chord is not in the center of the fishway. While the magnitudes of the pressure gradients of chords 1 and 2 are similar, there is a difference in the dynamics along these two chords. Along chord 1 a fish would experience more frequent dramatic changes in magnitude and direction of the pressure gradient and resulting forces.

The pressure distributions shown in Figs. 5-7 are in the x', y and z' directions, respectively, at a cross section near the midpoint of the length of the fishway. For comparison, the equivalent to these figures that would result from the static/uniform approach would have constant values of zero in the $\mathrm{x}$ ' and $\mathrm{y}$ directions, and a gradient of $-9.71 \mathrm{kPa} / \mathrm{m}$ in the $\mathrm{z}$ direction. These figures reinforce the above discussion and further illuminate the range of pressure gradients a fish may encounter at a particular section.

The longitudinal location of the cross section illustrated in Figs. 5-7

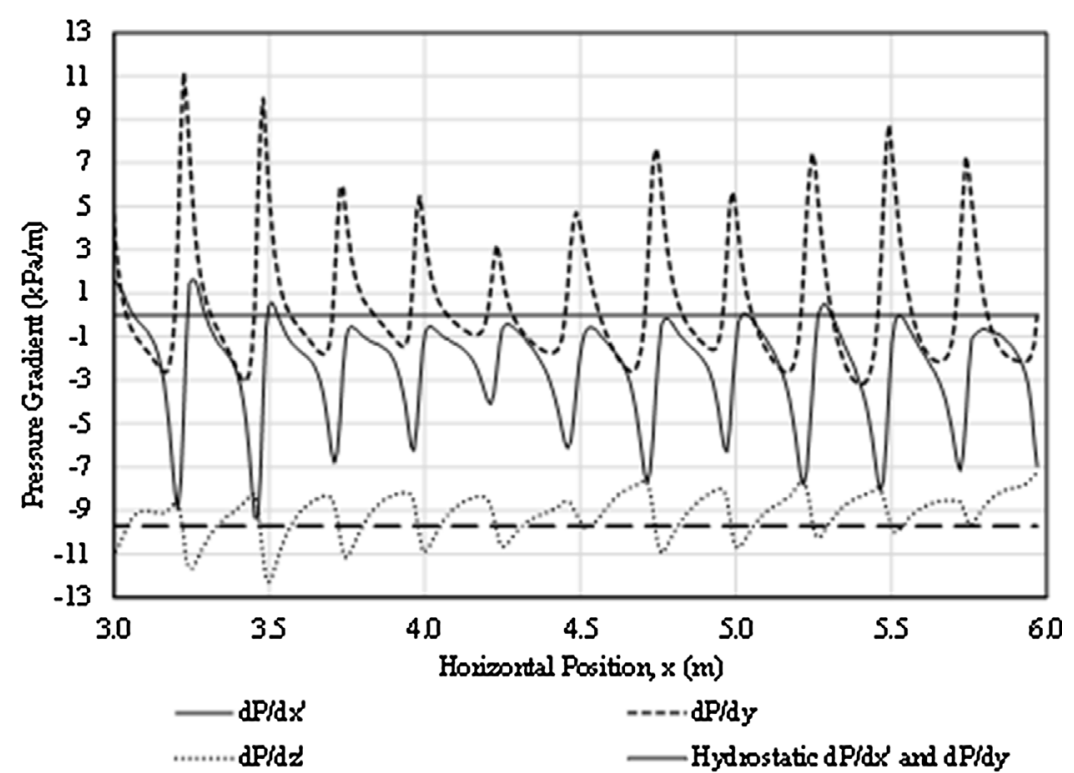

Fig. 3. Pressure gradients along chord 1 that is heavily influenced by proximity to the fishway baffles. 

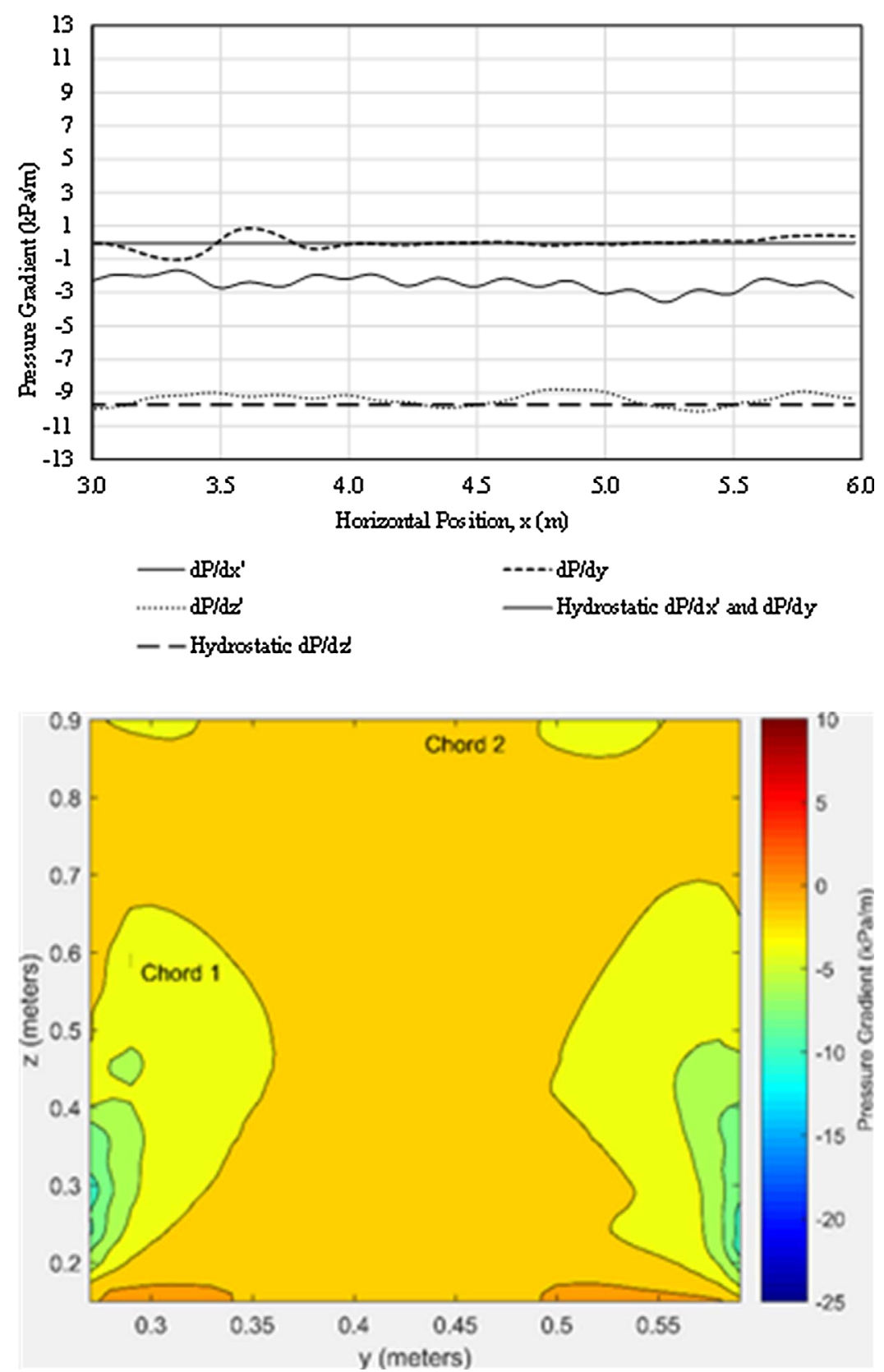

Fig. 4. Pressure gradients along chord 2 that is less influenced by proximity to the fishway baffles.
Fig. 5. Pressure gradient distribution in the $x^{\prime}$ direction at a vertical cross section. falls mid-baffle in a section of the fishway that is unaffected by inlet and outlet conditions. Fig. 5 shows the distribution of $x^{\prime}$ direction gradients. Again, the $\mathrm{x}^{\prime}$ gradients are those that would tend to propel or retard forward motion in the fishway. Fig. 5 illustrates that for the majority of the area in the cross section, there exists a slightly retarding (negative) pressure gradient. However, in proximity to the baffles, this retarding force increases significantly.

The distribution of y direction gradients (tending to push the fish side to side) is shown in Fig. 6. Much of the central portion of the cross section has relatively small pressure gradients. When close to the baffles the pressure gradients increase and are positive on one side and negative on the other. This indicates that the pressure gradients tend to propel toward the center of the fishway on both sides. An object in this position would need to counteract that gradient to stay in position.

Fig. 7 shows the distribution of pressure gradients in the $z^{\prime}$ direction (those typically described as resulting in buoyant forces). At the location of this cross section the pressure gradient is very near to the hydrostatic value of $-9.71 \mathrm{kPa} / \mathrm{m}$. This is because this cross section occurs at a point on both Figs. 3 and 4 where the dotted dP/dz' line is very close to the dashed hydrostatic $\mathrm{dP} / \mathrm{dz}$ ' line. The cross-sectional distributions in each case will change over the $0.25-\mathrm{m}$ baffle spacing as indicated by Figs. 3 and 4 . These results illustrate a significant difference in distribution and magnitude of pressure gradients from hydrostatic pressure distributions.

\section{Conclusions}

A deeper understanding of the pressure gradients that exist in the complex flow field of the steeppass fishway has been achieved by examining the results of a CFD simulation. Because the pressure gradients substantially impact the force balance, the gradients calculated for the steeppass cannot be considered hydrostatic or uniform. This assumption is a poor one for the steeppass fishway, but may be appropriate for other, less hydraulically dynamic, passage structures. Only pressure gradients acting on discrete volumes have been explored and the extension to a moving body was not. 

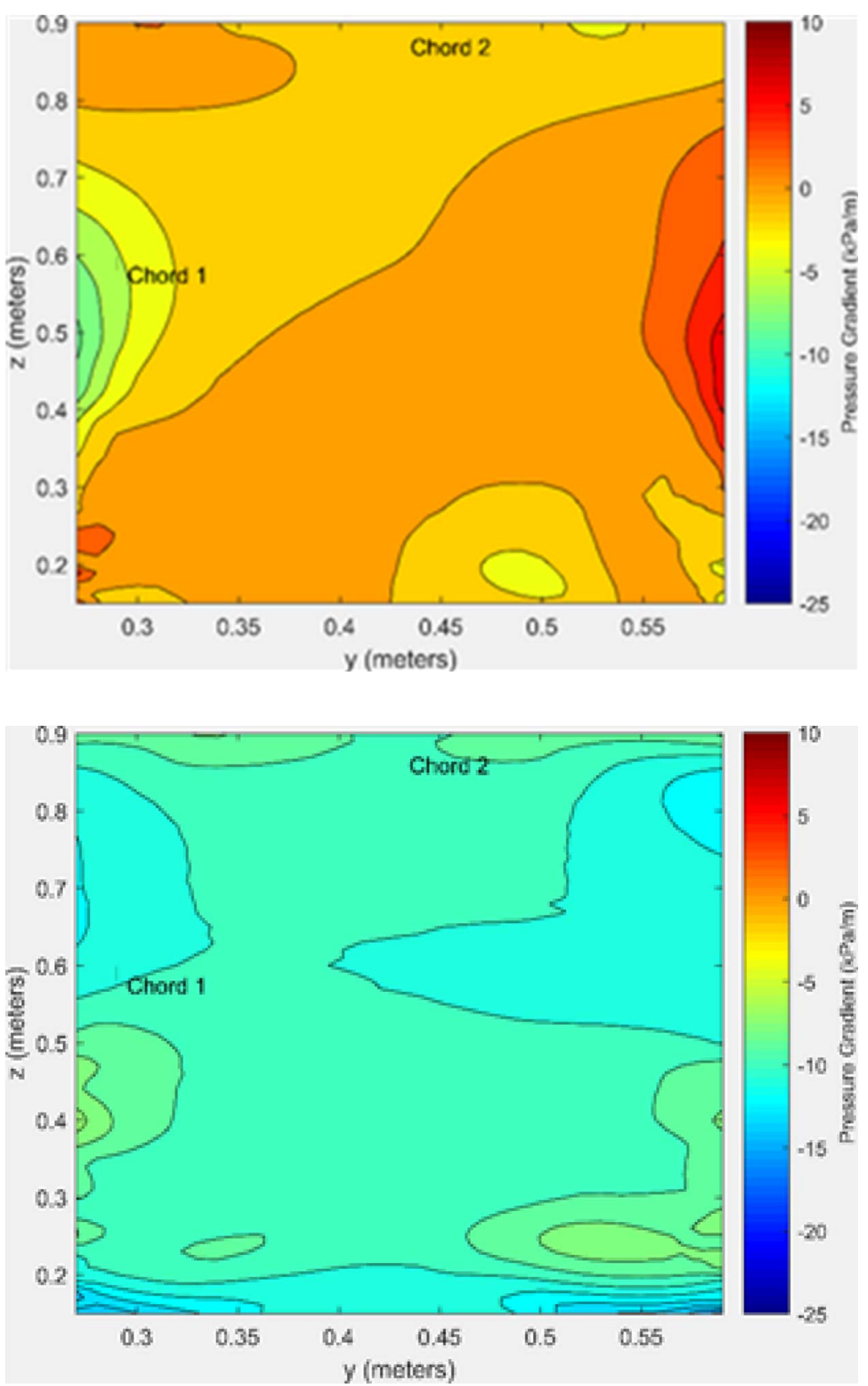

Fig. 6. Pressure gradient distribution in the y direction at a vertical cross section.
Fig. 7. Pressure gradient distribution in the z' direction at a vertical cross section.
This CFD simulation was originally developed to investigate passage of American shad. Utilizing a swim speed-fatigue model it was found that the velocities in the steeppass should not pose a problem for American shad (Plymesser, 2014) while previous research has shown mixed results for passage of these fish (Haro, 1999). In these earlier studies, it was suggested that there may be other hydraulic factors influencing passage. Examining the steeppass fishway using a CFD model indicates that the pressure gradients (and resulting forces) are of a magnitude to be considered relevant in this discussion. Unsteady forces may also be significant but were not pursued in this analysis. Unsteady effects can be computed from CFD model results in the future for comparison of magnitude.

\section{References}

Behlke, C.E., Kane, D.L., McLean, R.F., Travis, M.D., 1993. Economic Culvert design using fish swimming energy and power capabilities. Proceedings of the Fish Passage Policy and Technology Symposium, American Fisheries Society, Bioengineering Section
95-100.

Behlke, C.E., 1987. Hydraulic effects on swimming fish in fish passage structures. Hydr. Eng. 1116-1121.

Behlke, C.E., 1991. Power and energy implications of passage structures for fish. Am. Fish. Soc. Symp. 10, 289-298.

Blank, M.D., 2008. Advanced Studies of Fish Passage Through Culverts: 1D and 3D Hydraulic Modeling of Velocity, Fish Energy Expenditure, and a New Barrier Assessment Method Montana State University. PhD Dissertation.Advanced Studies of Fish Passage Through Culverts: 1D and 3D Hydraulic Modeling of Velocity, Fish Energy Expenditure, and a New Barrier Assessment Method Montana State University. PhD Dissertation.

Flow Science, 2012. Flow-3D (Version 10.0.3) and Flow 3-D User's Manual, Version 10.0 Flow Science, Inc.

Haro, A., Odeh, M., Castro-Santos, T., Noreika, J., 1999. Effect of slope and headpond on passage of american shad and blueback herring through simple denil and deepened alaska steeppass fishways. North Am. J. Fish. Manage. 19, 51-58.

Hirt, C.W., Nichols, B.D., 1981. Volume of fluid (VOF) method for the dynamics of free boundaries. J. Comput. Phys. 39 (1), 201-255.

Khan, L.A., 2006. A three-Dimensional computational fluid dynamics (CFD) model analysis of free surface hydrodynamics and fish passage energetics in a vertical slot fishway. North Am. J. Fish. Manage. 26, 255-267.

Odeh, M., 1993. Hydraulics of Alaska Steeppass Fishway Model A40. U.S Department of the Interior National Biological Survey, Turner Falls. 
Plymesser, K.E., 2014. Modeling Fish Passage and Energy Expenditure for American Shad in a Steeppass Fishway Using a Computational Fluid Dynamics Model Montana State University. PhD. Dissertation.Modeling Fish Passage and Energy Expenditure for American Shad in a Steeppass Fishway Using a Computational Fluid Dynamics Model Montana State University. PhD. Dissertation.

Rajaratnam, N., Katopodis, C., 1991. Hydraulics of steeppass fishway. Can. J. Civ. Eng. 18, 1024-1032.

Ren, Y., Liu, G., Han, P., Dong, H., Di Santo, V., Lauder, G., 2016. Swimming upstream: computational hydrodynamics of trout locomotion. Presented at the 69th Annual Meeting of the APS Division of Fluid Dynamics. http://dx.doi.org/10.1103/APS.DFD.
2016.GFMV0111.

Wada, K., Nobuyuki, A., Nakamura, S., 2000. Migratory behavior of juvenile ayu in denil and steeppass fishways in Japan. In: Odeh, M. (Ed.), Advances in Fish Passage

Technology. American Fisheries Society Bioengineering Section, pp. 103-114.

Webb, P.W., 1975. Hydrodynamics and Energetics of Fish Propulsion 190 Fisheries Research Board of Canada, Ottawa.

Yakhot, V., Smith, L.M., 1992. The Renormalization group, the E-Expansion and derivation of turbulence models. J. Sci. Comput. 1 (1), 35-61.

Ziemer, G.L., 1962. Informational Leaflet No. 12, Steeppass Fishway Development. Alaska Department of Fish and Game, Juneau. 